\title{
Legg-Calvé-Perthes hastalığında cihaz tedavisinin güncel değerlendirmesi
}

\section{Current evaluation of device therapy in Legg-Calvé-Perthes disease}

\author{
Güney Yılmaz
}

Hacettepe Üniversitesi Tıp Fakültesi Hastanesi, Ortopedi ve Travmatoloji Anabilim Dalı, Ankara

\begin{abstract}
Legg-Calvé-Perthes hastalığı (LCPH)'ndaki patolojik süreçler her geçen gün daha iyi anlaşılmasına rağmen, uygulanacak olan tedavi konusunda görüş birliği yoktur. LCPH'de tedavinin ana hedefi, femur başı ve asetabulum arasındaki uyumu sağlamaktır. Femur başı asetabulum içinde olduğu sürece, yeniden şekillenme sırasında femur başı yuvarlaklığını koruyacağı düşünülmektedir. Bu uyumu sağlamak amacıyla farklı konservatif ve cerrahi tedaviler uygulanmaktadır. Uygulanan konservatif tedavilerin başında ortez tedavileri gelir. Kullanılagelmiş farklı tipte ortezler olmakla beraber, hemen hepsinde kalça abduksiyonu ile beraber femur başının asetabulum içine santralizasyonu hedeflenmiştir. Literatürde, LCPH'de ortez tedavisinin etkinliğini değerlendiren karşılaştırmalı çalışma konusunda eksiklik vardır. Yapılan çalışmalarda, ortez tedavisinin, özellikle baş tutulumu yaygın olan Catterall Grup III/IV ve Herring Tip C olan hastalarda kötü sonuçlara neden olduğu belirtilmektedir. Küçük hastalarda (<6 yaş) ve baş tutulumu daha az yaygın olanlarda ortez tedavisi ile daha iyi sonuçlar elde edilebilmesine rağmen, diğer konservatif yöntemlere göre üstünlüğü gösterilememiştir. Bunun yanı sıra, ucuz olması, cerrahi skar olmaması ve takiplerde az radyografiye ihtiyaç duyulması nedeniyle, doğru seçilmiş hastalarda ortez tedavisi konservatif seçenekler arasında yerini korumaktadır.
\end{abstract}

Anahtar sözcükler: Legg-Calvé-Perthes; ortez; konservatif tedavi
Although the physiopathology behind the Legg-CalvéPerthes disease (LCPD) has been studied extensively, there is little agreement on the treatment protocol. The main target of the treatment in LCPD is to provide congruency of the femoral head and acetabulum. It is estimated that, as long as the femoral head is inside acetabulum the roundness of the femoral head will be ensured. To achieve this compliance, different conservative and surgical treatments are applied. One of the main conservative treatment option is brace treatment. Different types of braces have been utilized besides hip abduction, all of which aim to centralize the femoral head inside the hip joint. The literature lacks comparative studies on the effectiveness of brace treatment in LCPD. The studies on Catterall III/IV and Herring type $\mathrm{C}$ where the involvement of the femoral head is severe, indicates that the results are poor with the brace treatment. Although more favorable results can be obtained with brace treatment in younger patients ( $<6$ years) and in patients with less severe head involvement, the results are similar to other conservative treatments. On the other hand, brace treatment is cheap, causes no surgical scar and radiation exposure is less than the other treatments. With these advantages brace treatment is still an option as a conservative treatment method in selected patients.

Key words: Legg-Calvé-Perthes; brace; conservative treatment
egg-Calvé-Perthes hastalığı (LCPH), Legg, Calvé, Perthes ve Waldenstrom'un 105 yıl önce, immatür olan femur başı epifizinin osteonekrozisi olarak tanımladığı hastalıktır. Bilinmeyen bir şekilde femur başı kanlanmasının bozulmasıyla, proksimal femurun ossifik çekirdeği nekroza gitmekte ve daha sonra, rejenere olan kemiğin yeniden şekillenmesi sonucu patolojik bir durum oluşmaktadır. ${ }^{[1]}$

Epifız kıkırdağının mekanik desteği femur başındaki kemik stoktan sağlanır ve nekrotik kemik, yerini immatür kemik dokusuna bıraktıkça mekanik destek zayıflar. $^{[2,3]}$ Deforme olmaya müsait olan iyileşme dokusu nedeniyle, femur başının sferik şekli, dolayısıyla da femur-asetabulum arasındaki uyum bozulur.

Bazı olgularda hastalık kendini sınırlayabilmekte ve müdahale edilmeksizin sekelsiz iyileşebilmektedir. Ancak, birçok hastada rezidü kalça deformitesi nedeniyle erken osteoartrit gelişimi görülür. ${ }^{[4]}$

Hastalığın her geçen gün daha iyi anlaşılmaya başlanması ile birlikte, farklı tedavi yöntemleri

- Illetişim adresi: Dr. Güney Yılmaz, Hacettepe Üniversitesi Tıp Fakültesi Hastanesi, Ortopedi ve Travmatoloji Anabilim Dalı, Sıhhiye, Ankara Tel: 0312 - 3051209 e-posta: guney.yilmaz@hacettepe.edu.tr

- Geliș tarihi: 20 Șubat 2017 Kabul tarihi: 20 Șubat 2017 


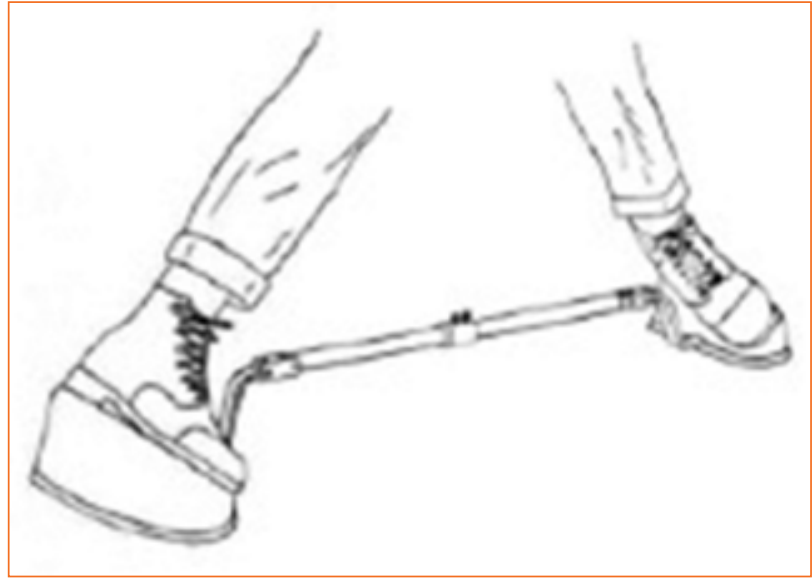

Şekil 1. Craig Bar ortezi.

tanımlanmıştır. Tedavideki asıl amaç; eklem ağrılarının giderilmesi, normal eklem hareket açıklığının sağlanması, normal femur-asetabulum ilişkisini koruyarak ileri yaşlarda ortaya çıkabilecek kalça dejenerasyonunun önüne geçilebilmesidir. Tedavide, mobilizasyonun kısıtlanmasından eklem hareket açıklığı egzersizlerine, ortez tedavilerinden asetabular ve femoral osteotomilere kadar birçok yöntem kullanılmaktadır. Perthes hastalığında, kötü prognozlu hastalar artık bilinmektedir. Henüz netleştirilemeyen konu ise, hangi hastada nasıl bir tedavi yönteminin izlenmesi gerektiğidir.

\section{ASETABULAR KAPSAMA KAVRAMI}

LCPH'de, başlarda tedavi olarak ekstremiteye yük vermekten koruyan tedaviler kullanılmıştır. Günümüzde ise LCPH tedavisi için daha çok asetabular kapsama teorisini temel alan yöntemler kullanılmaktadır. Teoriye göre; femur başı, oluşan nekroz sonucunda daha yumuşak ve şekillendirilebilir hale gelmektedir. Femur başı asetabulum içinde tutularak, asetabulumun mold edici etkisi ile, femur başının yuvarlak şekli korunabilir. Teori ilk olarak 1928'de Parker tarafından ortaya atılmıştır. ${ }^{[5]}$ Aynı teoriden yola çıkarak Salter, immatür ve ambulatuvar domuzlarda femur başı epifizinde, enfarkt sonrası dönemde "biyolojik plastisite" olduğunu göstermiştir. ${ }^{[6]}$ Buna göre, erken nekrotik dönemde yumuşak ve şekillenebilir hal alan femur epifizinin, abduksiyon ve iç rotasyon ile asetabulum tarafından kapsanması arttırılabilir, asetabulumun mold edici etkisinden yararlanılabilir ve epifiz deforme edici kuvvetlerden korunabilir. Femur başının asetabulum ile kapsanmasının yeterli olduğu domuzlarda normal sferik femur başı oluştuğu görülürken, kapsanmanın olmadığı femurlarda iyileşmenin dejenerasyon ve deformasyon ile devam ettiği görülmüştür. Sonuç olarak, Perthes tanılı hastalarda, femur başı asetabulum içinde tutularak, deforme edici kuvvetlerden korunabilir ve sferik şekli devam ettirilebilir. Femur başını asetabulum içinde santralize edecek yöntem olarak ortez tedavisi, bugün için popülerliğini yitirmiş olsa da, uzun yıllar kullanılmıştır. ${ }^{[5,7,8]}$

\section{ORTEZ TEDAVisi}

\section{Ortez Çeşitleri}

Femur başının asetabular kapsanmasının arttırılmasını ilke edinen ilk ortezlerden birisi, Craig Bar ortezidir (Şekil 1). Hastaların ayakkabılarına ve ayak bileklerine mediyalden monte edilen bu metal bar, ayak bileklerinin dış rotasyonunu engeller ve bacakları abduksiyonda tutar; ayakkabı tabanındaki kama şeklindeki destekler, subtalar eklemi nötralde tutmayı hedefler; ayak bileklerine verdiği pozisyon ve kalça abduksiyonu ile femur başını asetabuluma yönlendirir.

Salter'in "biyolojik plastisite" fikrini takip eden Mose, 1964'te, asetabular kapsanmayı sağlayan ortez tedavisini, kalça eklemi üstüne düşen yükleri yatak istirahati ile kısıtlayarak uygulamış; kapsama sorununu ortez ile ve femur başı üstündeki deforme edici kuvvetleri istirahat ile ortadan kaldırarak sorunu çözmeye çalışan Mose, istirahat halindeki hastalarda, ambulatuvar olanlara göre daha iyi sonuçlar yayımlamıştır. ${ }^{[7]}$ Aynı çalışmasında, ortez tedavisinin kalça hareket egzersizleriyle kombine edilmesinin daha iyi sonuç vereceğini belirtmiştir.

Perthes hastalığı ile adları sıkça anılmış olan Petrie ve Bitenic ise; uzun istirahat döneminin hastalar ve aileleri için zor olduğuna, femur başları asetabulum içinde olduğu sürece hastaların mobilize olmaları gerektiğine inanmışlardır. Bu yazarlar 1971 yılında, femur başlarını abduksiyon ve iç rotasyonda tutan, aynı zamanda hastaların ambulatuvar olmalarını sağlayan alçılama yöntemini bildirmişlerdir. Petrie alçısı olarak günümüzde anılan yöntem; femur başları asetabulum içindeyken yapılan bilateral uzun bacak alçılamayı takiben, her iki bacaktaki alçıları birleştiren ve kalçaları abduksiyon ile iç rotasyonda tutan metal barın uygulanmasını içerir. ${ }^{[8]}$ Tedavinin, asetabular kapsamayı sağlamakla birlikte birçok dezavantajı olduğu bildirilmiştir. Bu yöntemde, hastaların kalçaları uzun süre abduksiyonda kalmaktaydı ve alçı, 2-3 aylık periyodlarla değiştirilmekteydi. Eklemde sertlik gelişmesi, femur kondillerinde büyüme, bası yaraları, kas atrofileri gibi bildirilen komplikasyonlar, tedaviye uyumu bozan başlıca etkenler olarak öne çıkmaktaydı. 


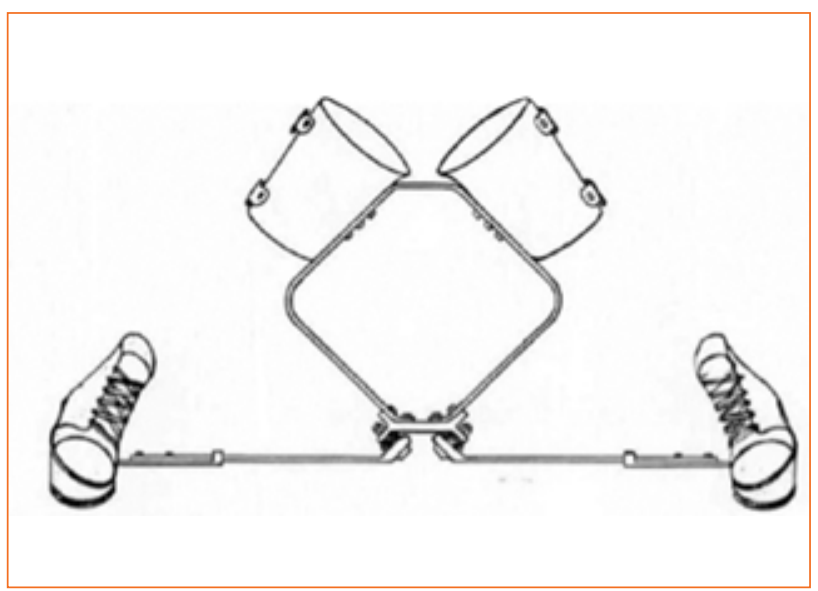

Şekil 2. Toronto ortezi.

Daha sonra kullanıma sunulan Toronto ve Newington ortezi gibi cihazlar, ara menteşeli bağlantıları sayesinde, hastaların diz fleksiyonunu yapabilmesini sağlamış ve böylelikle hem Petrie alçılamaya benzer başarı elde etmiş hem de ortez ile günlük hayatın idame edilmesini daha kolay hale getirmiştir (Şekil 2 ve 3).

1971 yılında Texas Scottish Rite Hastane'si, hasta aktivitesini daha az kısıtlayan, uyluk ve pelvik parça arasındaki menteşe ile femur başlarının hareketine ve yürümeye izin veren ortezleri kullanıma sunmuştur. $\mathrm{Bu}$ ortezde, (Şekil 4) pelvik bölgeye bağlanan kemer, diz

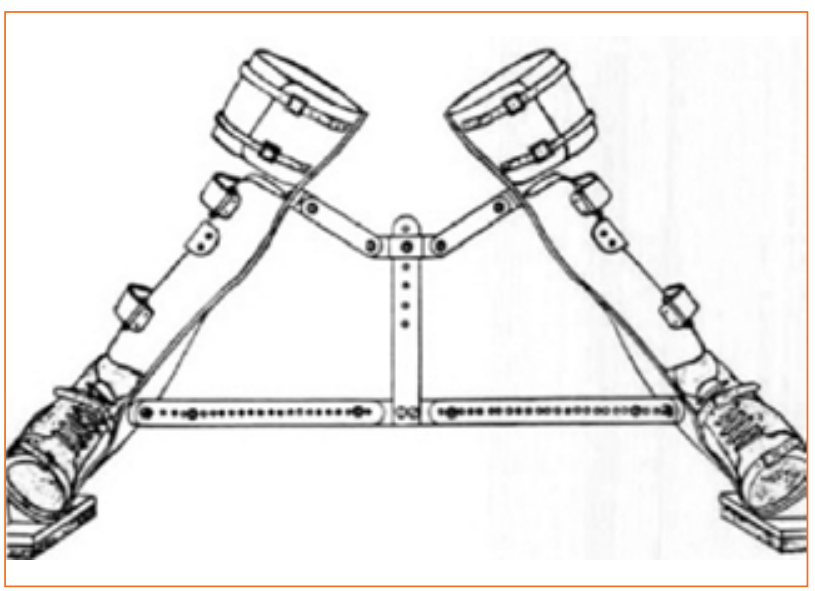

Şekil 3. Newington ortezi.

üzerine uygulanan aparatlara lateralden metal bar ile bağlıdır. ${ }^{[5]}$ Bu barlar, pelvik bölgedeki eklem yerlerine bağlanır ve bu hareketli bağlantılar ile kalça eklemi hareketi sağlar. Bu sayede, kalçalar abduksiyondayken, femur başları asetabulum içinde hareketli tutulabilmektedir. Bahsi geçen ortezler dışında pek çok farkIı ortez, Perthes hastalığı tedavisinde kullanılmıştır. Kullanılan ortezler, temelde kalça abduksiyonu üzerinden femur başı santralizasyonunu hedeflerken, zaman içinde kalça hareketini ve hasta mobilizasyonunu daha az kısıtlayan yapıya evrilmiştir.

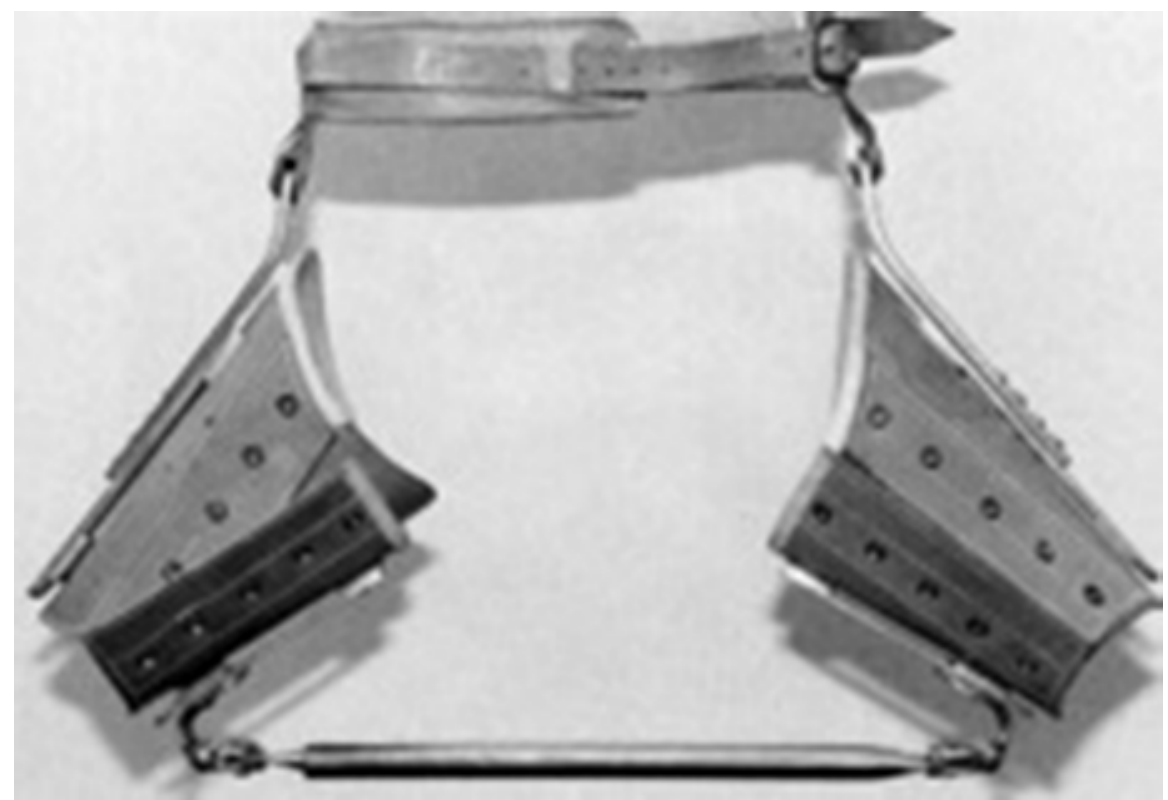

Şekil 4. Scottish Rite ortezi. 


\section{Tedavi Sonuçları}

Ortez kullanılmaya karar verilmiş bir hastada, abduksiyon ile beraber femur başı santralizasyonun gerçekleştiğinin ortaya konması gerekir. Yeterince abduksiyonu olmayan hastalarda ya da ortez içinde femur başı santralizasyonu gerçekleşmeyen olgularda, ortez tedavisi öncesinde/sırasında eklem hareket genişliğini arttırmak amacıyla, fizik tedaviye, cilt traksiyonuna, adduktor ve iliopsoas tenotomisi gibi yumuşak doku prosedürlerine ve menteşe tipi abduksiyon (hinge $a b$ duction) varlığından şüphelenilen olgularda artrografiye ihtiyaç duyulabilir.

Perthes hastalığı tanısı alan çocuklar, femur başı tutulumun şiddetine ve yaşlarına göre farklı gruplara ayrılabilir. Yapılan bu gruplandırma ışı̆̆ında, ileriye dönük prognostik öngörüler oluşturulabilir. Femur başındaki etkilenen alanın az olduğu Catterall Grup I ve II, Salter Thompson Grup A, Herring Grup A olup altı yaş altındaki hastalar, herhangi bir tedaviye gerek kalmaksızın iyi prognoza sahiptir. Bu hasta grubunda sadece gözlem uygulanabilir. Catteral Grup III ve IV, Herring Grup B, B-C ve C, Salter-Thompson Grup B olan ve altı yaş üstü hastalar ise, kapsayıcı tedaviler açısından aday hastalardır. Bu gruptaki hastalarda en uygun tedavi şeçeneğini belirlemek, Perthes literatürünü asıl meşgul eden konudur.

Herring, 337 hastanın (345 kalça) değerlendirildiği çok merkezli çalışmasında, farklı tedavi yöntemlerinin sonuçlarını yayınlamıştır. Hastalık başlangıcında yaşları 6-12 arasında değişen hastalar; tedavi verilmeyen, eklem hareket genişliği egzersizleri uygulanan, ortez tedavisi uygulanan, femoral osteotomi uygulanan ve pelvik osteotomi uygulanan grup olmak üzere, toplam beş farklı tedavi protokolü ile takip edilmişlerdir. Tedavi verilmeyen, eklem hareket genişliği egzersizleri verilen ve ortez uygulanan hastalar arasında, yaştan bağımsız olarak herhangi bir fark bulunamamıştır. Herring Tip B ve B/C sınır grupta olup sekiz yaşından büyük hastalarda cerrahi sonuçlar, cerrahi olmayan sonuçlara göre daha iyi bulunmuştur. Sekiz yaşından küçük ve Herring Tip $B$ hastalarda ise, cerrahi ve cerrahi olmayan sonuçlar benzer bulunmuştur. Herring Tip $\mathrm{C}$ olan hastalarda sonuçlar, tedaviden ve yaştan bağımsız olarak kötü rapor edilmiştir. Bu bakımdan bakıldığında, ortez tedavisi, Herring Tip $C$ kalçası olanlarda ve sekiz yaşından büyük Herring Tip $B$ ve $B / C$ sınır grup hastalarda önerilmemektedir. Diğer hastalarda, tedaviler arasında fark bulunmamakla beraber ortez tedavileri gündeme gelebilir. ${ }^{[9]}$ Yapılan başka bir çalışmada, altı yaşından küçük olan ve femur başının \%50'sinden fazlasında tutulum olan hastalarda fizyoterapi, Scottish Rite ortezi ve femur varus osteotomisi karşılaştırılmıştır. Beş yıllık takipte Stulberg I/ II elde edilen hastaların yüzdeleri sırasıyla \%53, \%46, $\% 52$ olmuştur. ${ }^{[10]}$ En düşük yüzde ortez tedavisinde elde edilmiş olsa da, bu tedaviyle varus osteotomisi gibi morbiditesi yüksek bir tedaviye yakın başarı oranı elde edilmesi önemlidir. Skaggs ve Tolo, ortez ile kapsayıcı tedaviyi altı yaşından küçük hastalara önerirken, yedi yaş ve üzeri hastalarda cerrahi tedavileri önermişlerdir. ${ }^{[1]}$ Rich ve arkadaşları tarafından yapılan bir çalışmada, parçalanma (fragmantasyon) ve nekroz evresinde tedaviye başlanan 240 hasta sunulmuştur. Adduktor tenotomi ve abduksiyon alçısını takip eden dönemde fizik tedavi ve ortez tedavisi kombine edilerek uygulanan tedavi protokolü ile, Herring Tip B ve $C$ kalçalarda dahi, femur başı örtünmesinin hastaların \%87'sinde iyi olduğu ve uyumlu kalçalar elde edilebildiği bildirilmiştir. ${ }^{[11]}$ Bunun aksine, Martinez ve arkadaşları tarafından sunulan çalışmada, Catterall III ve IV kalçalarda Scottish Rite ortezi sonuçlarının yedi yıllık takiplerde iyi olmadığı ve sadece izlem ya da fizik tedavi uygulanan hastalarla benzer olduğu ortaya konmuştur. Tedavi edilen 31 hastanın 22 (\%65) kalçası, son takipte, Mose'un femur başının yuvarlaklığını değerlendirdiği kriterlere göre kötü olarak değerlendirilmiştir. ${ }^{12]}$ Meehan ve arkadaşları tarafından sunulan benzer bir çalışmada, tanı anında altı yaş ve üstü olan 34 Perthes hastası (Catterall III/IV) değerlendirilmiştir. Hastalar, Scottish Rite ortezi kullanmışlardır ve uzun dönem takiplerinde yalnızca \%8'inde iyi sonuç elde edilebilmiştir. Bu iki çalışmada da kontrol grubu olmaması bir eksilik olarak belirtilmiştir, fakat yazarlar yaygın baş tutulumu olan hasta grubunda ortez tedavisini önermediklerini belirtmektedirler. ${ }^{[5]}$

Aksoy ve arkadaşları, 2004 yılında, ortez tedavisi uygulanan ve uygulanmayan iki grup Perthes hastasını karşılaştırdıkları çalışmalarını sunmuşlardır. Ortez tedavisi uygulanmayan hasta grubunu; tedaviyi kabul etmeyen hastalar, ortez verilmesine rağmen kullanmayan hastalar ve doktor tarafından tedavi önerilmemiş hastaların oluşturduğu çalışmada, ortalama takip süresi 12 yıldır. İki grup arasında; tedavi öncesi yaş, cinsiyet, Herring sınıflaması açısından fark bulunamamıştır. Hasta sonuçları Stulberg sınıflamasına göre değerlendirildiğinde; Stulberg Sınıf I ve II ile iyileşenlerin oranı ortez grubunda $\% 65$, ortez verilmeyen grupta ise $\% 53$ olarak bildirilmiştir. Ortez grubunda yüzde daha yüksek olsa da istatistiksel bir fark saptanmamıştır. ${ }^{[13]}$ Herring Tip A olan hastaların hepsinde, Tip $B$ olan hastaların ise çoğunda iyi sonuçlar elde edilirken, Tip $C$ kalçalarda tedaviden bağımsız kötü sonuçlar elde edilmiştir (Şekil 5 ve 6). 

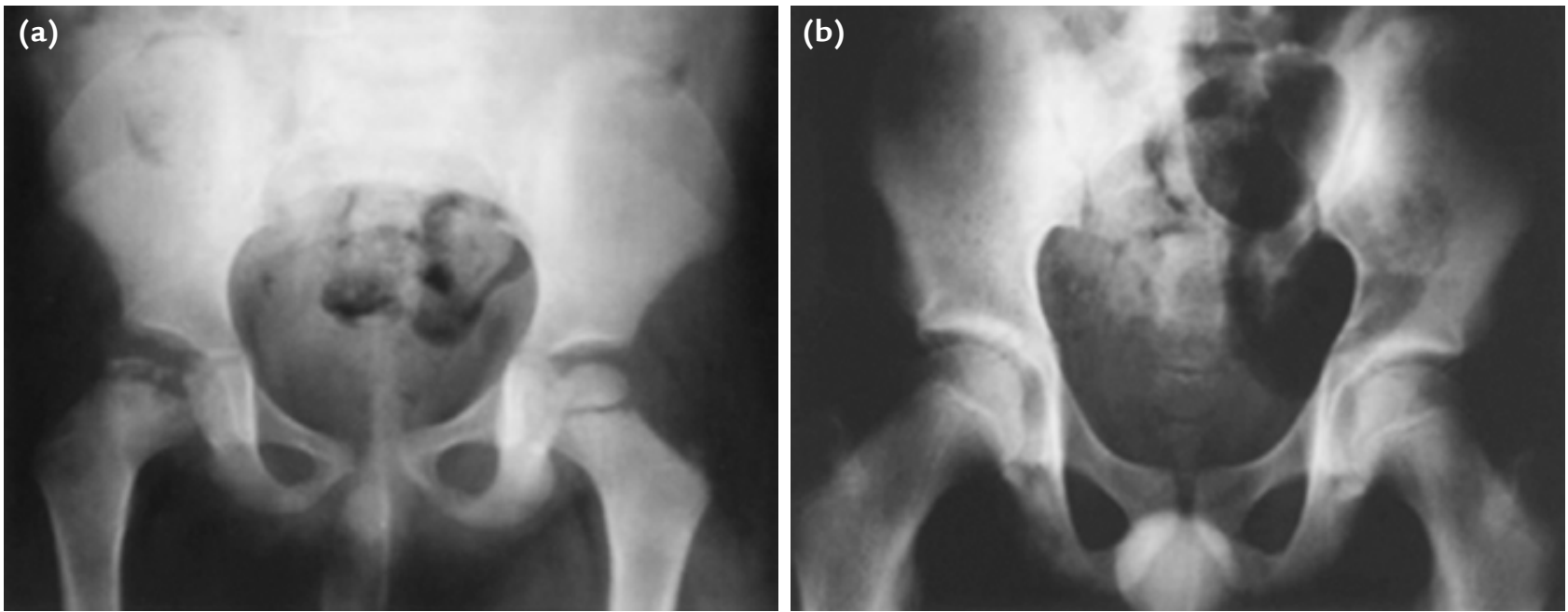

Şekil 5. a, b. Yedi yaşında, sağ kalçasında Herring Tip C Perthes hastalığı olan erkek hasta (a). Ortez tedavisi uygulanan hastanın 10 yılık takip radyografisi kalçanın Stulberg I ile iyileştiğini gösteriyor (b). (Dr. Cemalettin Aksoy'un izniyle kullanılmıştır)
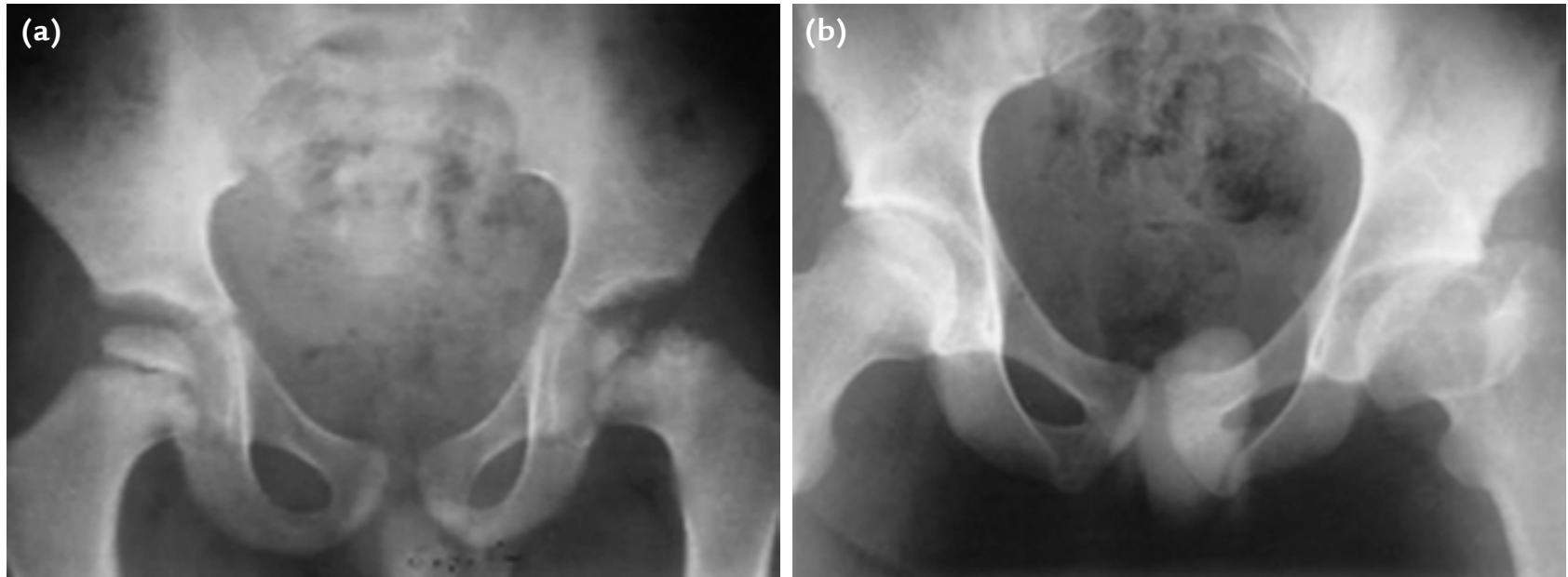

Şekil 6. a, b. Yedi yaşında erkek hasta. Sol kalçasında Herring Tip C Perthes hastalığı mevcut (a). On iki yıl sonraki takip radyografisinde sol kalçanın Stulberg III ile iyileştiği görülmekte (b). (Dr. Cemalettin Aksoy’un izniyle kullanılmıştır)

Literatür, ortez tedavisinin etkinliğini diğer yöntemlerle karşılaştıran randomize çalışmalar açısından fakirdir. Yapılan çalışmalardan, genel olarak, baş tutulum miktarı fazla olan, ileri yaş hastalarda prognoz üzerinde etkinliğinin kısıtlı olduğu sonucu çıkarılabilir. Küçük yaştaki hastalarda ve baş tutulumu daha kısıtlı olanlarda doğal seyri etkin biçimde değiştirebildiği yönünde güçlü kanıtlar bulunmamaktadır.

Ortez tedavisi uygulanan hastanın, 3-4 ayda bir kalça hareketleri açısından muayene edilmesi ve ön-arka pelvis grafisinde kalça uyumunun değerlendirilmesi önerilmektedir. Skaggs ve Tolo, yazdıkları bir derleme makalede, ortez tedavisinin sonlandırma zamanı konusunda kesin bir kural olmadığını belirtirler. Bununla birlikte, kendi hastalarında lateral epifizde ortaya çıkan yeni kemikleşme (re-ossifikasyon) sonrası bırakılabileceğini belirtmişlerdir. ${ }^{[11]}$ Herring, aynı şekilde, lateral epifiz kemikleşmesini göz önünde bulundurmuştur ve 12 aydan daha uzun süre kullanmaya gerek olmadığını belirtmiştir. ${ }^{[14]}$

LCPH'de ortez tedavisi; cerrahi tedavilere göre daha ucuzdur, skar oluşturmaz ve takiplerde daha az radyografi ihtiyacı vardır. Buna karşın, daha uzun tedavi ve takip süresi gerektirir; hasta uyumu daha düşüktür. Belirli bir hasta grubunda iyi sonuçların alınabildiği rapor edilse de, günümüzde gittikçe daha az uygulanan bir yöntem olarak karşımıza çıkmaktadır. 


\section{KAYNAKLAR}

1. Skaggs DL, Tolo VT. Legg-Calvé-Perthes Disease. J Am Acad Orthop Surg 1996;4(1):9-16.

2. Kim HK, Legg-Calvé-Perthes diease. J Am Acad Orthop Surg 2010;18(11):676-86.

3. Salter RB. Current concepts review. The present status of surgical treatment for Legg-Perthes' disease. J Bone Joint Surg 1984;66A:961-6. Crossref

4. Catterall A. The natural history of Perthes' disease. J Bone Joint Surg Br 197;53(1):37-53.

5. Meehan PL, Angel D, Nelson JM. The Scottish Rite abduction orthosis for the treatment of Legg-Perthes disease. J Bone Joint Surg Am 1992;74(1):2-12.

6. Salter RB. Legg-Perthes disease: the scientific basis for the methods of treatment and their indications. Clin Orthop Relat Res 1980;(150):8-11.

7. Mose K, Hjorth L, Ulfeldi M, Christensen ER, Jensen A. Legg Calvé Perthes disease. The late occurrence of coxarthrosis. Acta Orthop Scand Suppl 1977;169:1-39.

8. Petrie JG, Bitenc I. The abduction weight-bearing treatment in Legg-Perthes' disease. J Bone Joint Surg Br 1971;53(1):54-62.
9. Herring JA. The treatment of Legg-Calvé-Perthes disease. A critical review of the literature. J Bone Joint Surg Am 1994;76(3):448-58.

10. Wiig O, Terjesen T, Svenningsen S. Prognostic factors and outcome of treatment in Perthes' disease: a prospective study of 368 patients with five-year follow-up. J Bone Joint Surg Br 2008;90(10):1364-71. Crossref

11. Rich MM, Schoenecker PL. Management of Legg-Calvé-Perthes disease using an A-frame orthosis and hip range of motion: a 25-year experience. J Pediatr Orthop 2013;33(2):112-9. Crossref

12. Martinez AG, Weinstein SL, Dietz FR. The weight-bearing abduction brace for the treatment of Legg-Perthes disease. J Bone Joint Surg Am 1992;74(1):12-21.

13. Aksoy MC, Caglar O, Yazici M, Alpaslan AM. Comparison between braced and non-braced Legg-Calvé-Perthes disease patients: a radiological outcome study. J Pediatr Orthop B 2004;13(3):153-7.

14. Herring JA, Williams JJ, Neustadt JN, Early JS. Evolution of femoral head deformity during the healing phase of LeggCalvé-Perthes disease. J Pediatr Orthop 1993;13(1):41-5. 